
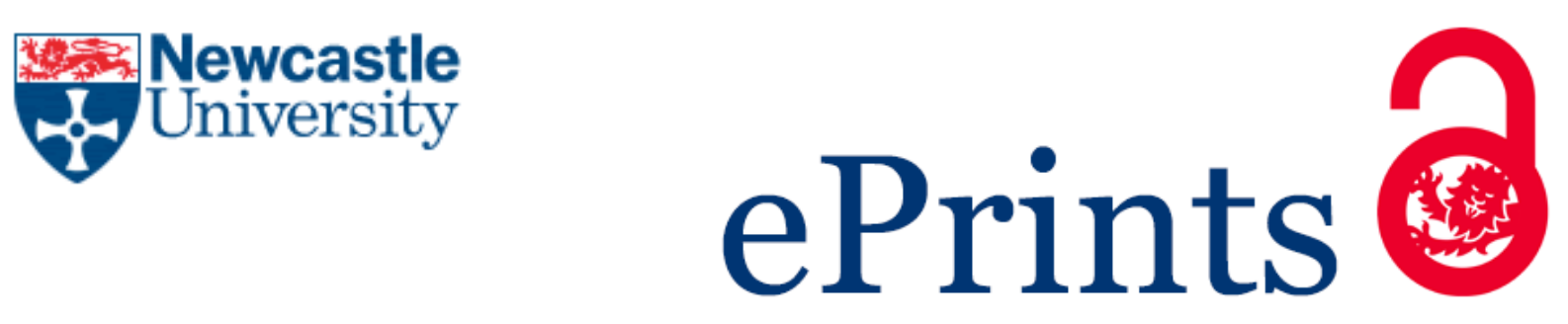

Pander P, Bulmer R, Martinscroft R, Thompson S, Lewis FW, Penfold TJ, Dias FB, Kozhevnikov VN.

1,2,4-Triazines in the Synthesis of Bipyridine Bisphenolate ONNO Ligands and Their Highly Luminescent Tetradentate Pt(II) Complexes for SolutionProcessable OLEDs. Inorganic Chemistry 2018 DOI: https://doi.org/10.1021/acs.inorgchem.7b03175

\title{
Copyright:
}

This is an open access article published under a Creative Commons Attribution (CC-BY) License, which permits unrestricted use, distribution and reproduction in any medium, provided the author and source are cited.

DOI link to article:

https://doi.org/10.1021/acs.inorgchem.7b03175

Date deposited:

$15 / 03 / 2018$

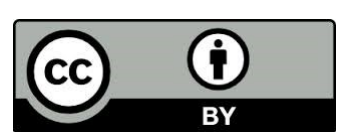

This work is licensed under a Creative Commons Attribution 4.0 International License 


\section{1,2,4-Triazines in the Synthesis of Bipyridine Bisphenolate ONNO Ligands and Their Highly Luminescent Tetradentate Pt(II) Complexes for Solution-Processable OLEDs}

Piotr Pander, ${ }^{\dagger}$ Rachel Bulmer, ${ }^{\ddagger}$ Ross Martinscroft, ${ }^{\ddagger}$ Stuart Thompson, ${ }^{\S}$ Frank W. Lewis, ${ }^{\ddagger(0)}$

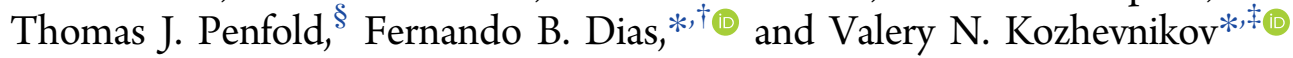

${ }^{\dagger}$ Department of Physics, Durham University, Durham, South Road, DH1 3LE U.K.

${ }^{\ddagger}$ Department of Applied Sciences, Faculty of Health and Life Sciences, Northumbria University, Newcastle upon Tyne, Tyne and Wear, NE1 8ST U.K.

${ }^{\S}$ School of Chemistry, Newcastle University, Bedson Building, Newcastle upon Tyne, NE1 7RU U.K.

Supporting Information

ABSTRACT: This article describes a convenient method for the synthesis of ONNO-type tetradentate 6,6'-bis(2-phenoxy)-2,2' -bipyridine (bipyridine bisphenolate, BpyBph) ligands and their platinum(II) complexes. The methodology includes the synthesis of 1,2,4-triazine precursors followed by their transformation to functionalized pyridines by the Boger reaction. Two complementary routes employing 3,3'- and 5,5'bis-triazines allow a modification of the central pyridine rings in different positions, which was exemplified by the introduction of cyclopentene rings. The new ligands were used to prepare highly luminescent ONNO-type Pt(II) complexes. The position of the cyclopentene

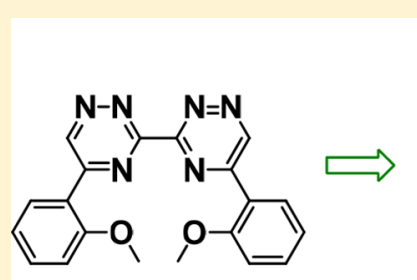
Improved solubility rings significantly influences the solubility and photophysical properties of these complexes. Derivatives with closely positioned cyclopentene rings are soluble in organic solvents and proved to be the best candidate for solution-processable organic lightemitting devices (OLEDs), showing efficient single-dopant candlelight electroluminescence.

\section{INTRODUCTION}

Tetradentate dianionic salen ONNO ligands are well known in coordination chemistry, and their metal complexes have found applications in a variety of scientific fields ranging from catalysis to bioinorganic and materials chemistry. For example, highly luminescent $\mathrm{Pt}(\mathrm{II})$ complexes of salen have been used as dopants in organic light-emitting diodes (OLEDs). ${ }^{1}$ The tetradentate nature of the ligand reduces the possibility of ligand-exchange reactions and benefits both the stability and the luminescence properties of these complexes. Classical salen ligands are easily prepared by the condensation of salicylic aldehyde derivatives with the corresponding diamines. However, the resulting $\mathrm{C}=\mathrm{N}$ imine bonds are prone to hydrolysis and other degradation pathways. To solve this problem, 6,6'-bis(2-phenoxy)-2,2'-bipyridine (bipyridine bisphenolate, BpyBph) were developed as a more robust system. Indeed, ONNO-type $\mathrm{Pt}(\mathrm{II})$ complexes of BpyBph and their phenanthroline analogues (PhenBph) showed strong luminescence in solution at room-temperature, good performance in OLEDs, and excellent thermal stability ${ }^{2}$ (Figure 1). It should be noted that the performance of the complexes strongly depends on the rigidity and the substitution pattern of the ligand, with values of the photoluminescent quantum yield in solution varying from as low as $5 \%$ in BpyBph systems to as high as $58 \%$ in PhenBph-based complexes. Clearly, for BpyBph platinum(II) complexes there is room for the improvement of luminescence properties.
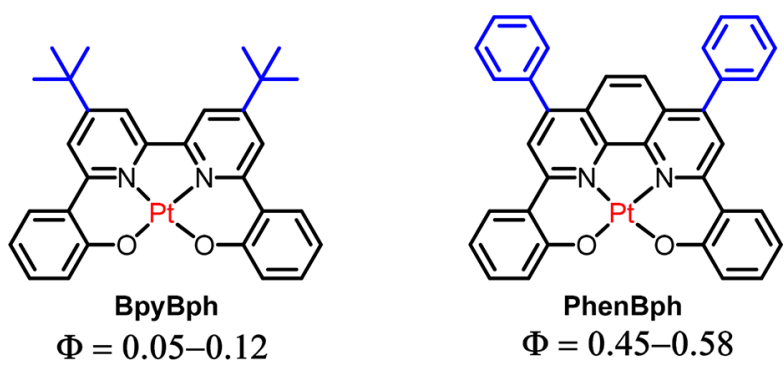

Figure 1. Structures of bipyridine bisphenolate (BpyBph) and phenanthroline bisphenolate (PhenBph) ligands reported by Che and co-workers. ${ }^{2}$

The synthesis of BpyBph ligands is more challenging than that of salen ligands, and there are only a few examples of such ligands described in the literature. The synthesis involves the reaction of 2,2'-bipyridine with 2-methoxyphenyllithium to give $6,6^{\prime}$-bis(2-methoxyphenyl)-2,2'-bipyridine, which is then demethylated to give the target ligand. ${ }^{3}$ Because highly nucleophilic reagents are used $(n-\mathrm{BuLi})$, only a limited number of functional groups can be tolerated in the ligand. In this article, we demonstrate a convenient method for the synthesis of BpyBph ligands based on the chemistry of 1,2,4-triazines. This methodology was

Received: December 18, 2017 
Scheme 1. Synthesis of Salen-Type BpyBph Proligands and Their Pt(II) Complexes ${ }^{a}$

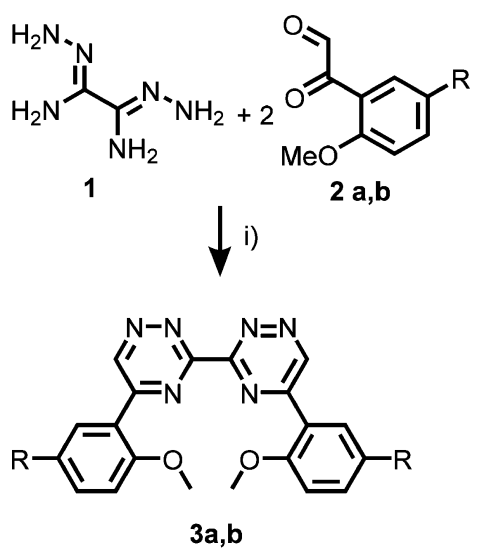<smiles>[R]Oc1ccc([R])cc1-c1ncc(C(C)C)nn1</smiles>

8a-Et: $\mathrm{R}=\mathrm{H}, \mathrm{R}^{2}=\mathrm{C}_{2} \mathrm{H}_{5}$

8b-Me: $\mathrm{R}=t-\mathrm{Bu}, \mathrm{R}^{2}=\mathrm{CH}_{3}$<smiles>[R]Oc1ccc([R])cc1-c1nncc(-c2cnnc(-c3cc([R])ccc3O[R])n2)n1</smiles>

9 a-Et, b-Me

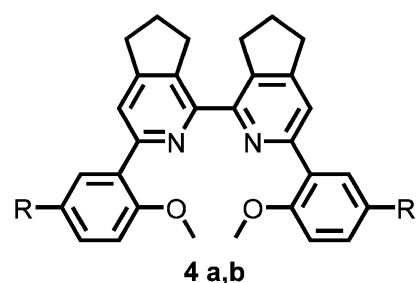

iii)

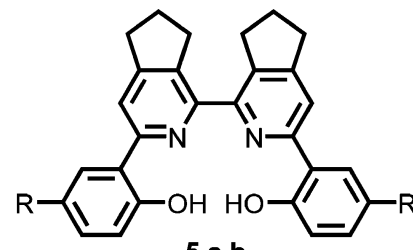

5 a,b

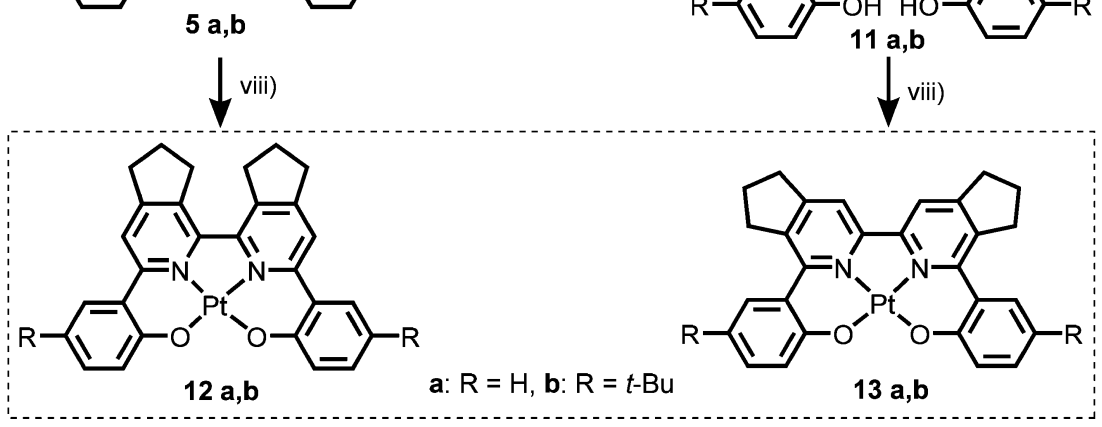

${ }^{a}$ Reaction conditions: (i) ethanol, reflux, 4-24 h; (ii) either 1-morpholino- or 1-pyrrolidinocyclopentene, please refer to experimental part for exact reaction conditions for a particular isomer; (iii) pyridinium chloride, $200-210^{\circ} \mathrm{C}, 2-6 \mathrm{~h}$; (iv) hydrazine hydrate, ethanol, $0-25^{\circ} \mathrm{C}$ for $14 \mathrm{~h}$ then $40 \%$ glyoxal, reflux $1 \mathrm{~h}$; (v) 3-t-butyl-5-methoxyphenyl boronic acid, CuMeSal, $\mathrm{Na}_{2} \mathrm{CO}_{3}, \mathrm{Pd}\left(\mathrm{PPh}_{3}\right)_{4}$, THF, reflux; (vi) KCN, 1,4-dioxane/water, RT, $14 \mathrm{~h}$; (vii) $\mathrm{BBr}_{3}, \mathrm{RT}, 14 \mathrm{~h}$; (viii) $\mathrm{K}_{2} \mathrm{PtCl}_{4}, \mathrm{AcOH}$, reflux, 14-16 h.

previously employed to prepare a variety of polypyridine ligands ${ }^{4}$ as well as their cyclometalated analogues. ${ }^{5}$ The key aspect of the methodology is that 1,2,4-triazines can be easily prepared from readily available starting materials and then transformed to their corresponding pyridines by the Boger reaction with enamines. In this way, a variety of substituents can be introduced into the pyridine ring. In this article, we report two synthesis routes employing 3,3' - and 5,5'-bis-triazines as key building blocks in preparing four novel ligands. We then show that the ligands readily form $\mathrm{Pt}(\mathrm{II})$ complexes, which are highly luminescent and can successfully be used as dopants in solution-processed OLEDs. In this study, we concentrate exclusively on solution-processed OLEDs and demonstrate that the position of cyclopenteno units plays a key role in increasing the solubility of the complexes.

\section{RESULTS AND DISCUSSION}

Synthesis. The synthesis of the novel salen-type proligands is depicted in Scheme 1. Because the N1 and N2 atoms of the triazine ring are lost during the Boger reaction as dinitrogen, we are limited to using 3,3'- and 5,5'-bis-triazines as key building 
blocks in the synthesis. $3,3^{\prime}$-Bis-triazines $\mathbf{3} \mathbf{a}$ and $\mathbf{3} \mathbf{b}$ were prepared in moderate yields by the reaction of corresponding glyoxal derivatives $\mathbf{2 a}$ and $\mathbf{2} \mathbf{b}$ with ethanedihydrazonamide (1). In order to prepare $5,5^{\prime}$-bis-triazine $(9 \mathrm{a}-E t)$, we started with commercially available 2-ethoxybenzamidine (6), which was treated with 1 equiv of hydrazine hydrate to give the corresponding amidrazone. ${ }^{6,7}$ The amidrazone was not isolated but was used in situ in the reaction with glyoxal to give $8 \mathbf{a}-E t$ in $66 \%$ yield. tert-Butyl derivative $\mathbf{8 b}-\mathbf{M e}$ was synthesized by the desulfurative Suzuki reaction of sulfide 7 with commercially available 3-tertbutyl-5-methoxyphenyl boronic acid. ${ }^{8}$ The next step involved the dimerization of 1,2,4-triazines $8 \mathbf{a}-E t$ and $8 \mathbf{b}-\mathrm{Me}$ by the action of potassium cyanide. This high-yielding reaction was first reported in $1973^{\circ}$ and has already been applied to the synthesis of bipyridines. $^{10} 3,3^{\prime}$-Bis-triazines $3 \mathbf{a}$ and $3 \mathbf{b}$ and $5,5^{\prime}$-bis-triazines 9a- $E t$ and $9 \mathbf{b}$-Me were then converted to $2,2^{\prime}$-bipyridines $4 \mathbf{a}$ and $4 \mathbf{b}$ and $10 \mathrm{a}-E t$ and $10 \mathrm{~b}-\mathrm{Me}$, respectively, by the Boger reaction with 1-morpholinocyclopentene. Finally, $\mathrm{O}$-demethylation with pyridinium chloride or boron tribromide under standard conditions gave the desired salen-type pro-ligands $\mathbf{5 a}$ and $\mathbf{5 b}$, and $11 \mathrm{a}$ and $11 \mathrm{~b}$. Complexes $12 \mathrm{a}$ and $12 \mathrm{~b}$, and $13 \mathrm{a}$ and $13 \mathrm{~b}$ were then prepared by the reaction of the corresponding proligands with potassium tetrachloroplatinate in refluxing acetic acid.

It was immediately apparent that $\mathbf{1 2 a}$ is far more soluble than 13a. One explanation for this might be that the cyclopentene units in 12a cause a slight twist of the pyridine rings, reducing the planarity of the molecule and thus minimizing the intermolecular interaction. Indeed, computational data supports this argument and shows that 12a is less planar than 13a (Figure 2).

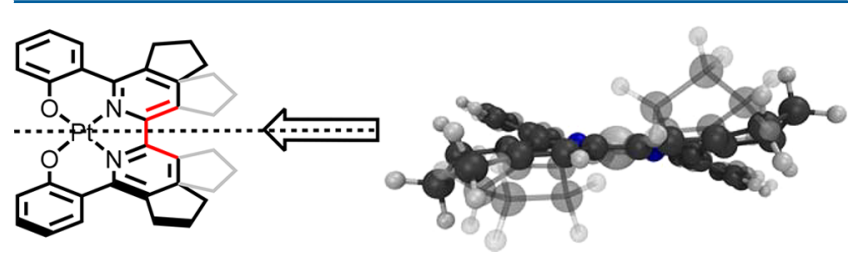

Figure 2. Comparison of optimized structures 12a (gray) and 13a (black).

Interestingly, the introduction of the tert-butyl groups did not significantly improve the solubility in both series of complexes in toluene. Only 12a dissolves well in toluene, while other complexes have very limited solubility. For this reason, all of the solution-processed OLEDs in this work were made using chlorobenzene as the solvent.

Luminescent Properties. The small changes in the ligand structure between $\mathbf{1 2}$ and $\mathbf{1 3}$ cause noticeable differences in the photophysical properties of the complexes. For example, in toluene solution, 13a, which is an isomer of $\mathbf{1 2 a}$ differing only by the position of the cyclopentene ring, has a more blue-shifted emission spectrum relative to that of 12a. A similar trend is observed in $\mathbf{1 2 b}$ and $\mathbf{1 3 b}$.

The photoluminescence spectra in solution (Figure 3) are nearly featureless and relatively broad, but when dispersed in a rigid and nonpolar polymer (Zeonex), the spectra show a more resolved vibronic structure. Interestingly, the phosphorescence spectra of each pair of analogues in Zeonex (12a and 12b, 13a and $\mathbf{1 3 b}$ ) are nearly identical, although they differ in solution. This indicates that the difference in the emission color of tertbutylated and nonsubstituted analogues is mostly a result of additional vibrational/rotational modes in tert-butylated molecules and the electron-donating effect of this group is less important.
At $77 \mathrm{~K}$, all four complexes display well-resolved, blue-shifted emission. In all cases, the $0-0$ transition is the strongest in the spectrum. Within each group of complexes (12a and 12b, 13a and $13 b)$, the low-temperature phosphorescence spectra show a very similar shape with identical vibronic structure, but the analogues with tert-butyl groups $(\mathbf{1 2 b}, \mathbf{1 3 b})$ give more red-shifted spectra than do their counterparts (12a and 13a). This is, in fact, an indication that the electronic effect of the tert-butyl group is significant. In general, notable rigidochromism is observed in these complexes, showing that the molecules are susceptible to intramolecular motion and interactions at room temperature. In both series, the introduction of the tert-butyl group reduces the luminescence yield, $\Phi_{\mathrm{PL}}$, which is probably due to the larger number of vibrational/rotational modes. Molecules with cyclopentene rings on the outer periphery of the bipyridine moiety (13a, 13b) have a larger $\Phi_{\mathrm{PL}}$ than do the corresponding isomers (12a, 12b).

This argument is supported by the phosphorescence lifetime measurements. In toluene solution, 13a shows the longest phosphorescence lifetime, whereas $\mathbf{1 2 b}$ shows the shortest. Shorter phosphorescence time constants in $\mathbf{1 2 b}$ and $\mathbf{1 3 b}$ are also found compared to their corresponding analogues (12a and 13a). We attribute the shorter phosphorescence lifetime of $12 b$ and $13 b$ relative to their analogues (12a and $13 a)$ to the increased nonradiative decay. All decay profiles recorded in toluene are perfectly monoexponential as shown in Figure 3. The photophysical properties of complexes $12 a, 12 b, 13 a$, and $13 b$ are summarized in Table 1 .

Electrochemistry. Cyclic voltammetry studies on complexes 12a, 12b, 13a, and $13 b$ show that all compounds behave similarly and show a reversible reduction that involves the $\mathrm{NN}$ (bipyridine) ligands. The oxidation of the complexes is, however, irreversible. In this case, the behavior of 12a and 13a is nearly identical, and this is also observed for their tert-butylated analogues, $\mathbf{1 2 b}$ and $\mathbf{1 3 b}$ (Figure 4, Table 2). This indicates that the oxidation of these complexes involves the phenyl rings of the OO ligand, as alkyl substitution of this moiety changes the electrooxidation signal pattern. This means that the alkyl- and nonalkyl-substituted complexes undergo different chemical reactions upon oxidation. The complexes have very similar oxidation and reduction potentials, but 13a and 13b have a larger electrochemical energy gap (0.05$0.07 \mathrm{eV}$ ), which explains the observed blue shift of their emission in comparison to that of the other two molecules.

Theory and Computational Chemistry. To support the interpretation of the experimental results, we have performed density functional theory (DFT) and time-dependent density functional theory (TDDFT) simulations on 12a and 13a, with the primary focus of rationalizing the structural and emission properties. The structure of the lowest triplet states was optimized using DFT(B3LYP) $)^{12}$ and a def2-SVP basis set as implemented within the ORCA quantum chemistry package. ${ }^{13}$ The excited-state energies were computed using linear responsetime-dependent density functional theory (LR-TDDFT) using the Tamm-Damcoff approximation and the B3LYP exchange and correlation functional as implemented within the Amsterdam Density Functional (ADF) code. ${ }^{14}$ The SOC matrix elements were computed with the perturbative approach developed by Wang and Ziegler. ${ }^{15}$ A DZP basis set was used for all atoms, except $\mathrm{Pt}(\mathrm{TZP})$, and scalar relativistic effects were accounted for using the zeroth-order relativistic approximation (ZORA). ${ }^{16}$

Figure 5 shows HOMO and LUMO orbitals, which constitute the dominant transitions responsible for both the $S_{1}$ and $T_{1}$ excited states. These correspond to charge-transfer states, from 

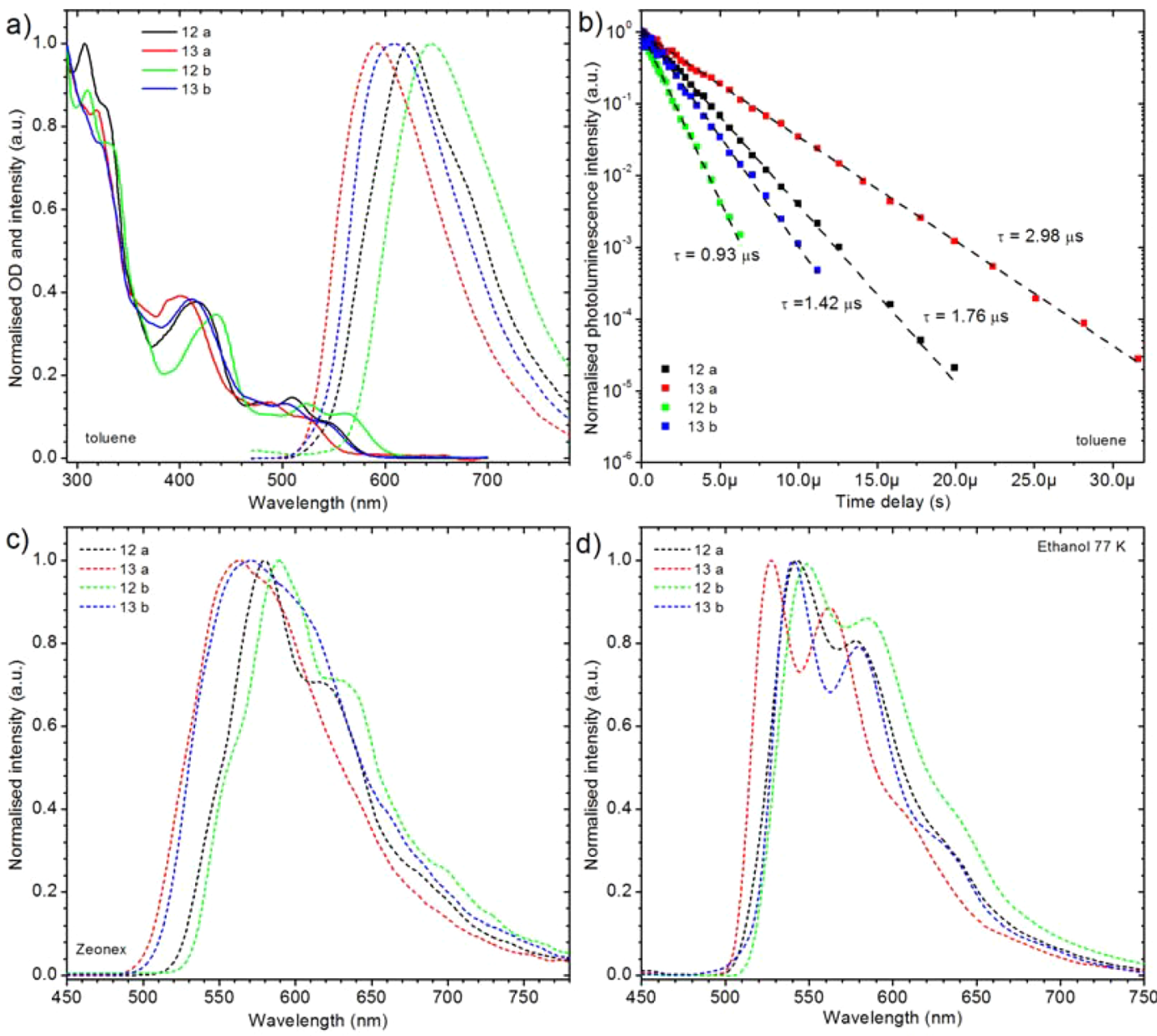

Figure 3. Photophysical characterization of Pt complexes: (a) absorption and phosphorescence spectra in toluene at room-temperature, $\lambda_{\text {exc }}=400 \mathrm{~nm}$; (b) phosphorescence decay in toluene at room temperature, $\lambda_{\text {exc }}=355 \mathrm{~nm}$; (c) Phosphorescence spectra in Zeonex 480 at room temperature, $\lambda_{\text {exc }}=400 \mathrm{~nm}$; (d) phosphorescence spectra in ethanol glass at $77 \mathrm{~K}, \lambda_{\text {exc }}=400 \mathrm{~nm}$.

Table 1. Summary of the Photophysical Properties of the Complexes

\begin{tabular}{|c|c|c|c|c|c|c|}
\hline \multirow[b]{3}{*}{ solvent } & absorption & \multicolumn{5}{|c|}{ emission } \\
\hline & $\lambda_{\mathrm{abs}}, \mathrm{nm}\left(\varepsilon \times 10^{-4}, \mathrm{M}^{-1} \mathrm{~cm}^{-1}\right)^{a}$ & $\lambda_{\mathrm{em}}, \mathrm{nm}^{b}$ & $\tau, \mu \mathrm{s}^{c}$ & $\Phi_{\mathrm{PL}}{ }^{d}$ & $\lambda_{\mathrm{em}}, \mathrm{nm}^{e}$ & $\tau, \mu \mathrm{s}^{f}$ \\
\hline & toluene & toluene & & & Zeonex 480 & \\
\hline $12 \mathrm{a}$ & $541(0.22), 509$ (0.31), $478(0.27), 417(0.80), 329(1.85), 308$ (2.12) & 624 & $1.76 \pm 0.08$ & 0.24 & 580 & $7.6 \pm 0.4$ \\
\hline 13a & 527 (0.17), 489 (0.27), 399 (0.85), $320(1.80)$ & 593 & $2.98 \pm 0.14$ & 0.34 & 564 & $5.5 \pm 0.4$ \\
\hline $12 b$ & 564 (0.30), 523 (0.38), 488 (0.30), 436 (1.02), 335 (2.20), 310 (2.61) & 646 & $0.93 \pm 0.04$ & 0.12 & 589 & $5.4 \pm 0.2$ \\
\hline $13 \mathrm{~b}$ & $547(0.15), 506(0.26), 470(0.30), 410(0.80), 323(1.57)$ & 610 & $1.42 \pm 0.18$ & 0.25 & 572 & $4.8 \pm 0.4$ \\
\hline
\end{tabular}

${ }^{a}$ The absorption band wavelength and absorption coefficient with $\pm 15 \%$ error. ${ }^{b}$ The emission maxima in toluene. ${ }^{c}$ The phosphorescence lifetime at room-temperature in degassed solution. ${ }^{d}$ The photoluminescence quantum yield in degassed solution with $\pm 15 \%$ error. ${ }^{e}$ The emission maxima in a Zeonex polymer. ${ }^{f}$ The phosphorescence lifetime in Zeonex in vacuum.

the $\mathrm{OO}$ to the NN ligands for both complexes. The emission energy (which, following the large phosphorescence and Kasha's rule, corresponds to the $T_{1}$ state) for $12 \mathrm{a}$ is $629 \mathrm{~nm}$, and that for $13 \mathrm{a}$ is $590 \mathrm{~nm}$. The excited-state lifetimes (derived from the radiative rate) of 12a and 13a are 195 and $184 \mu$ s, respectively. The large difference between the experimental and calculated lifetimes is that the calculated lifetime does not include nonradiative effects, which are relatively significant in solution, as indicated by the lower quantum yields. For 12a and 13a, the SOC between $S_{1}$ and $T_{1}$ states is about $\sim 350 \mathrm{~cm}^{-1}$ in both cases.

OLED Fabrication and Characterization. Solution-processed devices were fabricated from complexes 12a, 12b, 13a, and $13 \mathbf{b}$ using chlorobenzene solutions of mixed host (PVK + PBD) and dopant. (see SI for more details about fabrication of devices.) The dopant concentration was limited in some cases due to the poor solubility of some of the complexes in chlorobenzene. For this reason, toluene could also not be used as a solvent, except for 12a, which was dissolved in toluene to produce a device with a $5 \%$ dopant concentration. Devices of 12a in toluene had performances that were similar to those of the presented chlorobenzene-based OLEDs. The poor solubility of complexes 13a and $\mathbf{1 3 b}$ resulted in a limited dopant concentration ( 1 and $3 \%$, respectively). This is likely to decrease the efficiency of host to dopant energy transfer (due to a limited Forster and Dexter radii) and cause problems with direct charge injection into the dopant, which in turn decreases the efficiency of the device. This is clearly 


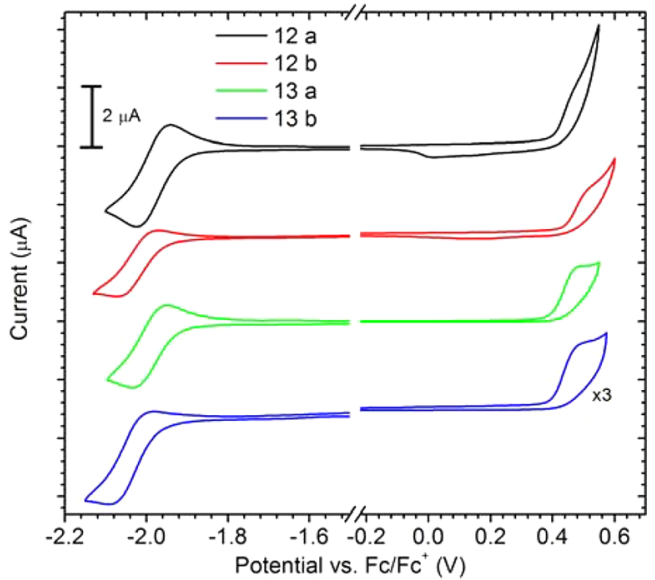

Figure 4. Electrochemical oxidation and reduction cycles of the investigated complexes recorded with cyclic voltammetry at a $0.05 \mathrm{~V} \mathrm{~s}^{-1}$ scan rate in $0.1 \mathrm{M} \mathrm{Bu}_{4} \mathrm{NBF}_{4} / \mathrm{DCM}$ supporting electrolyte. Note that the results for $\mathbf{1 3 b}$ were recorded at a lower concentration due to its limited solubility.

Table 2. Electrochemical Properties of the Investigated Complexes $^{a}$

$\begin{array}{cccccc}\text { complex } & E_{\mathrm{Ox}}{ }^{\mathrm{Cv}}, \mathrm{V}^{b} & E_{\mathrm{Red}}^{\mathrm{Cv}}, \mathrm{V}^{c} & \mathrm{Ip}, \mathrm{eV}^{d} & \mathrm{EA}, \mathrm{eV}^{e} & \mathrm{E}_{\mathrm{g}}^{\mathrm{El}}, \mathrm{eV}^{f} \\ \text { 12a } & 0.40 & -1.92 & 5.50 & 3.18 & 2.32 \\ \text { 13a } & 0.44 & -1.95 & 5.54 & 3.15 & 2.39 \\ \text { 12b } & 0.40 & -1.92 & 5.50 & 3.18 & 2.32 \\ \text { 13b } & 0.40 & -1.97 & 5.50 & 3.13 & 2.37\end{array}$

${ }^{a}$ Note All Potentials Are Relative to the Standard Potential of Ferrocene/Ferrocenium Redox Couple. ${ }^{b}$ Onset oxidation potential was recorded with cyclic voltammetry. ${ }^{c}$ Onset reduction potential was recorded with cyclic voltammetry. ${ }^{d}$ Ionization potential IP $=E_{\mathrm{ox}}{ }^{\mathrm{CV}}+$ 5.1. ${ }^{11}{ }^{e}$ Electron affinity EA $=E_{\text {red }}{ }^{C V}+5.1 .{ }^{f}$ Electrochemical energy gap $E_{\mathrm{g}}^{\text {el }}=$ IP - EA. IP and EA correspond to the HOMO and LUMO energy, respectively, and are used as their estimates. the problem in devices containing 13a. This is also shown in the photophysical study where, in the case of PVK:PBD films with low doping concentrations (complexes 13a and 13b), another, slower mechanism for energy transfer is observed (i.e., limited by hole-electron pair recombination ${ }^{17}$ ). When the photophysical data is compared with electroluminescence spectra it becomes clear that in OLEDs direct charge injection to the dopant is the dominant process, while energy transfer from host to guest is less dominant. On the other hand, energy transfer governs the photoluminescence in a PVK:PBD mixed host. For this reason, it is important that the efficiency of the OLED devices is slightly larger than it would be expected to be from photophysics.

The compounds perform well as dopants in OLEDs (Figure 6), giving electroluminescence from yellow-green to orange that is in full agreement with the photophysical results. All dopants except 12b give efficient devices with an EQE of $8.4-10.4 \%$ and a satisfactory current efficiency of $22.3-24.9 \mathrm{~cd} \mathrm{~A}^{-1}$. The brightness of these devices reached $7000 \mathrm{~cd} \mathrm{~m}^{-2}$ in the case of $12 \mathrm{a}$, while the device derived from $12 \mathrm{~b}$ shows the lowest brightness of $2500 \mathrm{~cd} \mathrm{~m}^{-2}$. The turn-on voltage is in the typical range for the OLED structure used with a PVK:PBD host. ${ }^{18}$

Because of the higher photoluminescence quantum yield both in doped film and in solution, the 13a-based OLED was expected to have a higher maximum EQE and in general to outperform the 12a-based OLED. However, the low solubility of the complex imposed limitations in doping concentration, and the device with 13a as the dopant $(1 \%)$ is therefore less efficient than the device incorporating 12a (5\%). The yellowish electroluminescence of devices 1 and 3 is close to that of candlelight, while device 2 has a more green and device 4 a more red electroluminescence. The colorimetric coordinates in the CIE 1931 color space of a typical candle $(0.52,0.42)^{19}$ and those of presented devices 1 and 3 are close to this value (see Table 3 ). Interestingly, the candlelight color has been achieved with the use of only one emitter whereas other solutions use 2 to 3 emitters. ${ }^{19-21}$
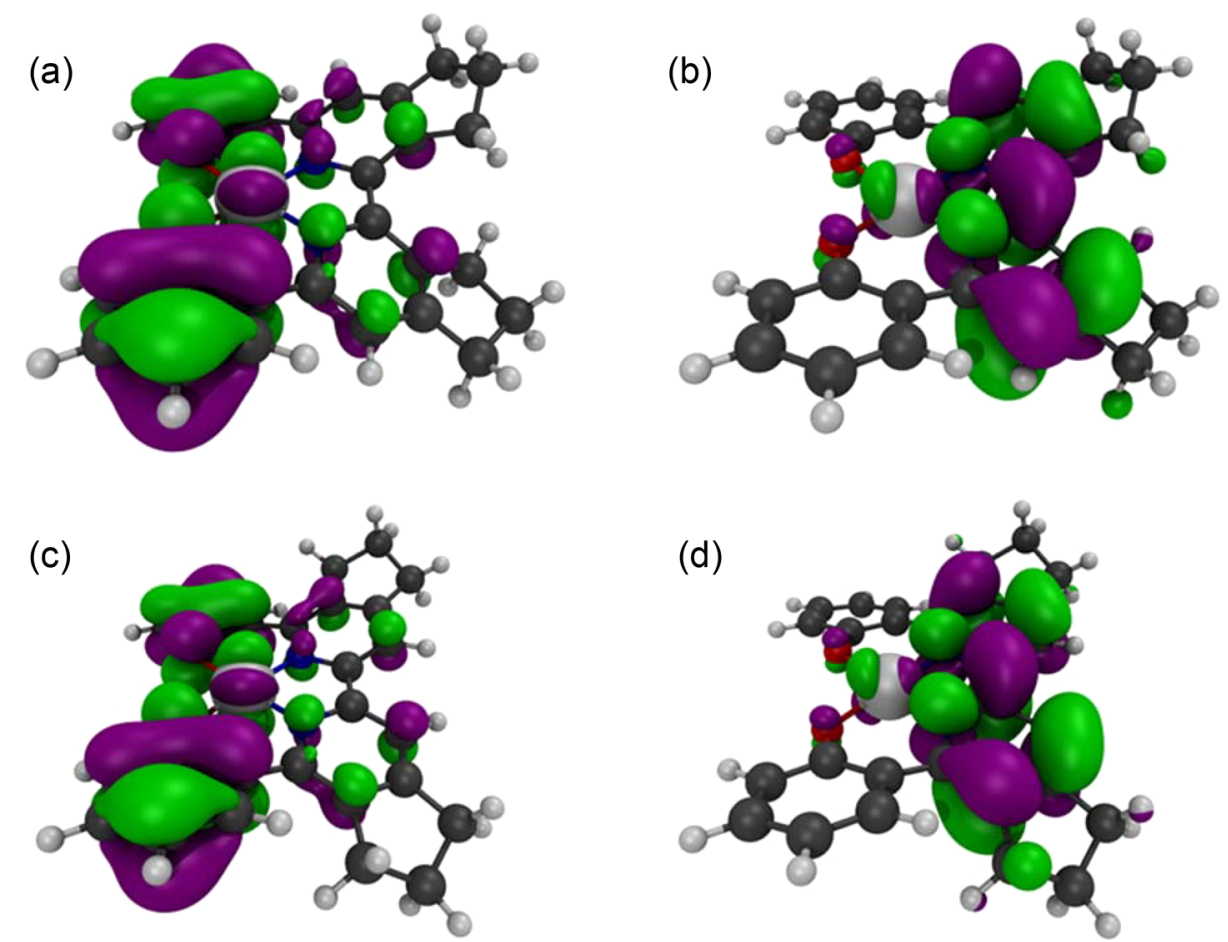

Figure 5. HOMO (a and c) and LUMO (b and d) orbitals of 12a (upper) and 13a (lower). 

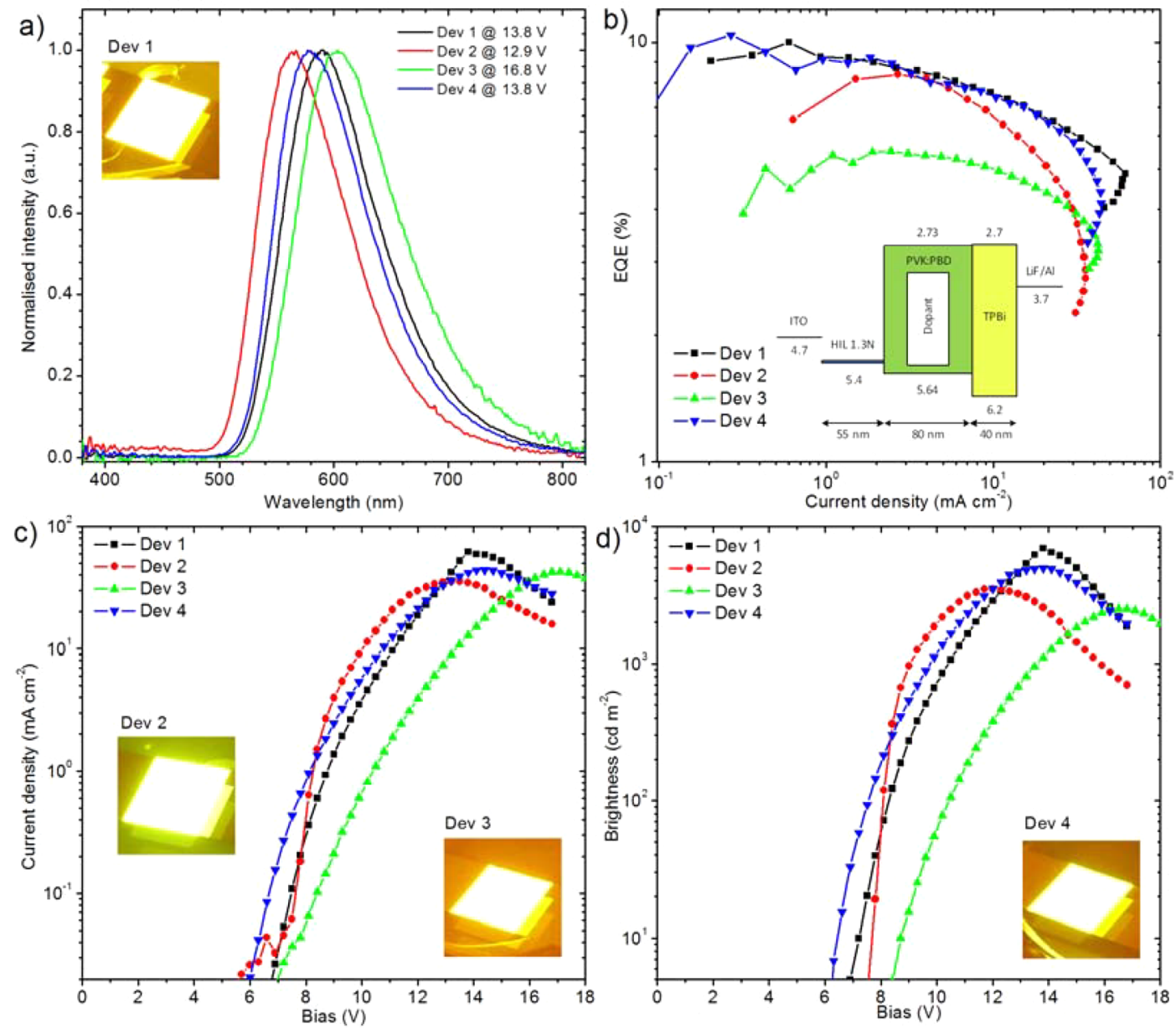

Figure 6. Characteristics of the OLED devices produced from 12a, 12b, 13a, and 13b: (a) electroluminescence spectra; (b) external quantum efficiency (EQE) vs current density; (c) $J-V$ curves; and (d) brightness vs bias. The insets are photographs of the working devices. The inset in panel (b) shows the device architecture.

Table 3. Summary of the Characteristics of the OLED Devices ${ }^{a}$

\begin{tabular}{|c|c|c|c|c|c|c|c|c|c|}
\hline \multirow[b]{2}{*}{ device } & \multirow[b]{2}{*}{ dopant } & \multirow[b]{2}{*}{$\begin{array}{l}\text { turn on at } \\
10 \mathrm{~cd} \mathrm{~m}^{-2}, \mathrm{~V}\end{array}$} & \multicolumn{3}{|c|}{ EQE, \% } & \multirow[b]{2}{*}{$\begin{array}{l}\text { max. current efficiency, } \\
\qquad \mathrm{cd} \mathrm{A} \mathrm{A}^{-1}\end{array}$} & \multirow[b]{2}{*}{$\begin{array}{l}\text { max. brightness, } \\
\mathrm{cd} \mathrm{m}^{-2}\end{array}$} & \multirow[b]{2}{*}{$\begin{array}{c}\mathrm{EL} \\
\text { maximum, nm }\end{array}$} & \multirow[b]{2}{*}{$\begin{array}{c}\mathrm{CIE}(x, y) \text { at max } \\
\text { brightness }\end{array}$} \\
\hline & & & $\max$. & at $100 \mathrm{~cd} \mathrm{~m}^{-2}$ & at $1000 \mathrm{~cd} \mathrm{~m}^{-2}$ & & & & \\
\hline Dev 1 & $12 \mathrm{a}$ & 7.2 & 10.0 & 9.7 & 8.2 & 23.2 & 7000 & 590 & $0.54,0.46$ \\
\hline Dev 2 & $13 \mathrm{a}$ & 7.6 & 8.4 & $6.6^{b}$ & 8.2 & 24.9 & 3500 & 567 & $0.46,0.51$ \\
\hline Dev 3 & $12 \mathrm{~b}$ & 8.7 & 5.5 & 5.3 & 4.9 & 9.9 & 2500 & 603 & $0.57,0.42$ \\
\hline Dev 4 & $13 \mathrm{~b}$ & 6.4 & 10.4 & 9.3 & 8.0 & 22.3 & 5000 & 577 & $0.52,0.47$ \\
\hline
\end{tabular}

${ }^{a}$ Device architecture: ITOIHIL 1.3N (55 nm)Idopant (1-5\%) co PVK:PBD (60:40) (80 nm)|TPBi $(40 \mathrm{~nm})|\mathrm{LiF}(0.8 \mathrm{~nm})| \mathrm{Al}(100 \mathrm{~nm})$. Doping concentration: Dev 1: 12a (5\%), Dev 2: 13a (1\%), Dev 3: 12b (5\%), Dev 4: 13b (3\%). ${ }^{b}$ The value was recorded at $118 \mathrm{~cd} \mathrm{~m}^{-2}$.

\section{CONCLUSIONS}

The synthesis methodology based on the chemistry of 1,2 , 4-triazines proved to be efficient and versatile in the synthesis of tetradentate dianionic bipyridine bisphenolate ONNO ligands. The scope of the methodology goes beyond luminescent complexes and is likely to attract attention from scientists in other fields. Many other functional groups can be introduced by the Boger reaction, opening up additional pathways for optimizing and tuning ONNO ligands for different applications. In Pt(II) complexes formed by the new ligands, the introduction of the tert-butyl groups was found not to improve solubility in toluene but reduced the quantum efficiency of the complexes and is thus not a good strategy for optimizing the dopants. However, the 1,2,4-triazine methodology illustrated herein does allow for the synthesis of more soluble isomers by positioning the cyclopentene rings closer together, leading to less-planar structures. This significantly improves the solubility of the complex, but the detrimental effects on the photophysical properties are less profound. This allowed us to obtain the required doping concentration to achieve efficient single-dopant candlelight OLED devices.

\section{EXPERIMENTAL SECTION}

The description of the materials and methods and experimental as well as experimental procedures for tert-butyl analogues are described in theSupporting Information.

5,5'-Bis(2-methoxyphenyl)-3,3'-bi-1,2,4-triazine (3a). $(1 Z, 2 Z)$-Ethanedihydrazonamide $(1)(1.16 \mathrm{~g}, 10 \mathrm{mmol})$ was suspended in ethanol $(75 \mathrm{~mL})$, and a $1 \mathrm{M}$ solution of 2-methoxyphenylglyoxal (2a) in ethanol $(22 \mathrm{~mL}, 22 \mathrm{mmol})$ was added. The reaction mixture was 
heated under reflux for $4 \mathrm{~h}$. The mixture was allowed to cool to ambient temperature, and the solid was filtered off, washed with ethanol $(20 \mathrm{~mL})$ followed by diethyl ether $(40 \mathrm{~mL})$, and allowed to dry in air to afford title compound 3a as a yellow-green solid (1.87 g, 50\%). ${ }^{1} \mathrm{H}$ NMR $\left(400.1 \mathrm{MHz}, \mathrm{CDCl}_{3}, \mathrm{Me}_{4} \mathrm{Si}\right) \delta: 10.12(\mathrm{~s}, 2 \mathrm{H}), 8.38(\mathrm{~d}, J=7.6,2 \mathrm{H}), 7.55$ $(\mathrm{t}, J=7.6,2 \mathrm{H}), 7.16(\mathrm{t}, J=7.6,2 \mathrm{H}), 7.06(\mathrm{~d}, J=8.8,2 \mathrm{H}), 3.99(\mathrm{~s}, 6 \mathrm{H})$; ${ }^{13} \mathrm{C}$ NMR (100.6 MHz, $\left.\mathrm{CDCl}_{3}, \mathrm{Me}_{4} \mathrm{Si}\right) \delta: 161.9,158.7,155.8,150.1$, 134.1, 132.2, 122.3, 121.8, 111.6, 55.8. HRMS (ESI) calcd for $\mathrm{C}_{20} \mathrm{H}_{17} \mathrm{~N}_{6} \mathrm{O}_{2}$ $\left([\mathrm{M}+\mathrm{H}]^{+}\right): m / z 373.1413$. Found: $m / z 373.1411$.

6,6'-Bis(2-methoxyphenyl)-2,2'-bipyridine (4a). 5,5' -Bis(2-methoxyphenyl)-3,3'-bi-1,2,4-triazine, $3 \mathrm{a}$ ( $2.3 \mathrm{~g}, 6.18 \mathrm{mmol})$, was placed in a round-bottomed flask and 1-morpholinocyclopentene ( $3.78 \mathrm{~g}, 4$ equiv) was added. The flask was heated at $140^{\circ} \mathrm{C}$ for $3 \mathrm{~h}$ and was then allowed to cool to $70^{\circ} \mathrm{C}$. Methanol $(30 \mathrm{~mL})$ was added and the mixture was stirred at reflux for $10 \mathrm{~min}$ and then allowed to cool to room-temperature. The solid was filtered and washed with $\mathrm{MeOH}(30 \mathrm{~mL})$ to give desired product $4 \mathbf{a}$ $(2.2 \mathrm{~g}, 79 \%) .{ }^{1} \mathrm{H}$ NMR $\left(400.1 \mathrm{MHz}, \mathrm{CDCl}_{3}, \mathrm{Me}_{4} \mathrm{Si}\right) \delta: 7.82$ (dd, $J=$ 7.6, 1.6, 2H), $7.67(\mathrm{~s}, 2 \mathrm{H}), 7.30-7.35(\mathrm{~m}, 2 \mathrm{H}), 7.05(\mathrm{t}, J=7.2,2 \mathrm{H}), 6.98$ $(\mathrm{d}, J=7.6,2 \mathrm{H}), 3.84(\mathrm{~s}, 6 \mathrm{H}), 3.33(\mathrm{t}, J=7.6,4 \mathrm{H}), 2.99(\mathrm{t}, J=7.6,4 \mathrm{H})$, 2.11 (quin, $J=7.6,4 \mathrm{H}) ;{ }^{13} \mathrm{C}$ NMR $\left(100.6 \mathrm{MHz}, \mathrm{CDCl}_{3}, \mathrm{Me}_{4} \mathrm{Si}\right.$ ) $\delta: 157.1,152.6,153.5, .155 .0,138.0,131.5,130.1,129.3,120.9,120.5$, 111.5 , 55.7, 33.0, 32.4, 25.2. HRMS (ESI) calcd for $\mathrm{C}_{30} \mathrm{H}_{29} \mathrm{~N}_{2} \mathrm{O}_{2}$ $\left([\mathrm{M}+\mathrm{H}]^{+}\right): m / z 449.2229$. Found: $m / z 449.2233$.

6,6'-Bis(2-hydroxyphenyl)-2,2'-bipyridine (5a). A mixture of 4 a $(1.80 \mathrm{~g}, 0.4 \mathrm{mmol})$ and pyridinium chloride $(18.0 \mathrm{~g}, 155.7 \mathrm{mmol})$ was stirred at $210^{\circ} \mathrm{C}$ for $6 \mathrm{~h}$. The mixture was allowed to cool to room temperature, and water $(50 \mathrm{~mL})$ was added. The solid was filtered off and washed sequentially with water and methanol to give $\mathbf{5 a}$ as a solid. Yield: $1.5 \mathrm{~g},(90 \%) .{ }^{1} \mathrm{H}$ NMR $\left(400.1 \mathrm{MHz}, \mathrm{CDCl}_{3}, \mathrm{Me}_{4} \mathrm{Si}\right) \delta: 7.89$ (s, 2H), 7.86 $(\mathrm{dd}, J=8.4,1.2,2 \mathrm{H}), 7.29(\mathrm{t}, J=8.4,2 \mathrm{H}), 6.99(\mathrm{dd}, J=8.4,0.8,2 \mathrm{H}), 6.92$ $(\mathrm{t}, J=8.4,2 \mathrm{H}), 3.13(\mathrm{t}, J=7.6,4 \mathrm{H}), 3.08(\mathrm{t}, J=7.6,4 \mathrm{H}), 2.14$ (quin, $J=7.6,4 \mathrm{H}) ;{ }^{13} \mathrm{C}$ NMR $\left(100.6 \mathrm{MHz}, \mathrm{CDCl}_{3}, \mathrm{Me}_{4} \mathrm{Si}\right) \delta: 159.7,158.0$, 155.0, 148.4, 138.0, 131.1, 126.2, 119.2, 118.8, 118.4, 115.2, 33.4, 31.6, 25.5. HRMS (ESI) calcd for $\mathrm{C}_{28} \mathrm{H}_{25} \mathrm{~N}_{2} \mathrm{O}_{2}\left([\mathrm{M}+\mathrm{H}]^{+}\right): m / z 421.1916$. Found: $m / z 421.1902$.

Platinum Complex 12a. A mixture of proligand $5 \mathrm{a}(105 \mathrm{mg}$, $0.25 \mathrm{mmol})$ and potassium tetrachloroplatinate $(104 \mathrm{mg}, 0.25 \mathrm{mmol})$ in acetic acid $(40 \mathrm{~mL})$ was heated under reflux for $14 \mathrm{~h}$. The solvent was evaporated. The product was purified by column chromatography using silica gel and a mixture of DCM/ethyl acetate (10/1). Yield $61 \mathrm{mg}$ (40\%). ${ }^{1} \mathrm{H} \mathrm{NMR}\left(400.1 \mathrm{MHz}, \mathrm{CDCl}_{3}, \mathrm{Me}_{4} \mathrm{Si}\right) \delta 7.65$ (s, 2H), 7.61 (br. d, $J=8.3,2 \mathrm{H}), 7.29(\mathrm{~m}, 2 \mathrm{H}), 7.24(\mathrm{dd}, J=8.4,1.1,2 \mathrm{H}), 6.69(\mathrm{~m}, 2 \mathrm{H}), 3.08$ (t, $J=7.1,4 \mathrm{H}$ ), $2.78(\mathrm{t}, J=7.1,4 \mathrm{H}$ ), 2.22 (quin, $J=7.1,4 \mathrm{H}$ ). HRMS (TOF) calcd for $\mathrm{C}_{28} \mathrm{H}_{23} \mathrm{~N}_{2} \mathrm{O}_{2}{ }^{194} \mathrm{Pt}\left([\mathrm{M}+\mathrm{H}]^{+}\right): m / z 613.1386$. Found: $m / z 613.1387$.

3-(2-Ethoxyphenyl)-1,2,4-triazine (8a-Et). To an ice-cold, stirred suspension of 2-ethoxybenzamidine hydrochloride $(10 \mathrm{~g}, 50 \mathrm{mmol})$ in ethanol $(50 \mathrm{~mL})$, hydrazine hydrate $(2.5 \mathrm{~g}, 50 \mathrm{mmol})$ was added. The mixture was stirred at 0 to $15^{\circ} \mathrm{C}$ overnight. A $40 \%$ aqueous glyoxal solution $(8.7 \mathrm{~g}, 0.6 \mathrm{~mol}, 1.2$ equiv) was added. The reaction was stirred for $20 \mathrm{~min}$ at room temperature and then gradually heated to reflux. The mixture was heated under reflux for $1 \mathrm{~h}$. Water $(250 \mathrm{~mL})$ was added, and the mixture was extracted with DCM $(3 \times 30 \mathrm{~mL})$. The organic phase was dried over $\mathrm{MgSO}_{4}$, filtered, and concentrated to a volume of $20 \mathrm{~mL}$. The product was purified by column chromatography on silica gel using DCM/ethyl acetate $1 / 1$ as an eluent. The solvent was evaporated to give a product as a yellow oil. Yield $6.63 \mathrm{~g}(66 \%)$. Analytical characteristics are identical to literature data. ${ }^{8 a}$

3,3'-Bis(2-ethoxyphenyl)-5, $5^{\prime}$-bi-1,2,4-triazine (9a-Et). 3-(2-Ethoxyphenyl)-1,2,4-triazine (8a-Et) $(2.01 \mathrm{~g}, 10 \mathrm{mmol})$ was stirred in a mixture of water $(50 \mathrm{~mL})$ and dioxane $(20 \mathrm{~mL})$ until complete dissolution occurred. $\mathrm{KCN}(850 \mathrm{mg}, 13 \mathrm{mmol})$ was added in two portions, $30 \mathrm{~min}$ apart. The mixture was stirred at $\mathrm{rt}$ overnight. The solid was filtered off and washed with water and methanol to give 9a-Et. Yield $1.65 \mathrm{~g}(82 \%) .{ }^{1} \mathrm{H}$ NMR $\left(400 \mathrm{MHz}, \mathrm{CDCl}_{3}\right) \delta 10.25(\mathrm{~s}, 2 \mathrm{H}), 7.99(\mathrm{dd}, J=$ $7.6,1.8,2 \mathrm{H}), 7.54(\mathrm{ddd}, J=8.3,7.6,1.8,2 \mathrm{H}), 7.16(\mathrm{ddd}, J=8.3,8.3,1.0$, $2 \mathrm{H}), 7.12$ (br. $\mathrm{d}, J=8.3,2 \mathrm{H}), 4.20(\mathrm{q}, J=6.9,4 \mathrm{H}), 1.43(\mathrm{t}, J=6.9,6 \mathrm{H})$; ${ }^{13} \mathrm{C}$ NMR $\left(100 \mathrm{MHz} \mathrm{CDCl}_{3}\right) \delta 165.4,157.9,150.8,143.96,132.7$, 132.1, 124.6, 120.8, 113.3, 64.5, 14.9. HRMS (ESI) calcd for $\mathrm{C}_{22} \mathrm{H}_{21} \mathrm{~N}_{6} \mathrm{O}_{2}$ $\left([\mathrm{M}+\mathrm{H}]^{+}\right): m / z$ 401.1726. Found: $m / z 401.1713$.
6,6'-Bis(2-ethoxyphenyl)-2,2'-bipyridine (10a-Et). 5,5'-Bis(2ethoxyphenyl)-3,3'-bi-1,2,4-triazine (9a-Et) (2.2 g, $5.5 \mathrm{mmol})$ was placed in a round-bottomed flask, and 1-pyrrolidinocyclopentene $(7.54 \mathrm{~g}$, $55 \mathrm{mmol}, 10$ equiv) was added. The flask was held at $140^{\circ} \mathrm{C}$ for $15 \mathrm{~min}$. Acetic acid $(30 \mathrm{~mL})$ was added, and the mixture was stirred at reflux for $10 \mathrm{~min}$. Methanol $(30 \mathrm{~mL})$ and water $(30 \mathrm{~mL})$ were added, and the mixture was allowed to cool to room temperature. The solid was filtered and washed with $\mathrm{MeOH}(30 \mathrm{~mL})$ to give the desired product $(2.1 \mathrm{~g}, 80 \%)$. The product was used without further purification. However, the product can be purified by recrystallization from acetic acid/methanol mixture. ${ }^{1} \mathrm{H}$ NMR $\left(400.1 \mathrm{MHz}, \mathrm{CDCl}_{3}, \mathrm{Me}_{4} \mathrm{Si}\right) \delta 8.30(\mathrm{~s}, 2 \mathrm{H}), 7.51$ (dd, $J=7.6,1.8,2 \mathrm{H}$ ), 7.35 (ddd, $J=8.3,7.6,1.8,2 \mathrm{H}$ ), 7.07 (br. t, $J=7.6,2 \mathrm{H}$ ), 7.12 (br. d, $J=7.6,2 \mathrm{H}), 4.0 .2(\mathrm{q}, J=7.0,4 \mathrm{H}), 2.98(\mathrm{t}, J=7.4,4 \mathrm{H}), 2.83$ $(\mathrm{t}, J=7.4,4 \mathrm{H}), 2.04$ (quin, $J=7.4,4 \mathrm{H}), 1.28(\mathrm{t}, J=6.9,6 \mathrm{H}) ;{ }^{13} \mathrm{C} \mathrm{NMR}$ $\left(100 \mathrm{MHz}, \mathrm{CDCl}_{3}\right), \delta 156.3,154.97,154.4,152.2,139.6,131.7,130.7$, $129.4,120.7,116.3,112.3,64.0,33.2,31.5,25.2,15.0$. HRMS (ESI) calcd for $\mathrm{C}_{32} \mathrm{H}_{33} \mathrm{~N}_{2} \mathrm{O}_{2}\left([\mathrm{M}+\mathrm{H}]^{+}\right): m / z$ 477.2542. Found: $m / z$ 477.2533.

BpyBph proligand (11a). At room temperature, $\mathrm{BBr}_{3}(4 \mathrm{~mL})$ was slowly added dropwise to the solution of $10 \mathrm{a}-\mathrm{Et}(500 \mathrm{mg}, 1.05 \mathrm{mmol})$ in $\mathrm{CH}_{2} \mathrm{Cl}_{2}(20 \mathrm{~mL})$. After the addition was complete, the mixture was stirred at room temperature under argon for $18 \mathrm{~h}$. The reaction was quenched by the slow addition of water. DCM $(30 \mathrm{~mL})$ was added, and the organic phase was separated, washed with water, dried, and filtered. The filtrate was filtered through a plug of silica gel. The silica gel was washed with DCM. The solvent was evaporated, and the residue was treated with methanol (5 mL) and filtered. Yield $190 \mathrm{mg}(43 \%){ }^{1} \mathrm{H} \mathrm{NMR}(400.1 \mathrm{MHz}$, $\left.\mathrm{CDCl}_{3}, \mathrm{Me}_{4} \mathrm{Si}\right) \delta 8.07(\mathrm{~s}, 2 \mathrm{H}), 7.76(\mathrm{dd}, J=7.8,1.6,2 \mathrm{H}), 7.33$ (ddd, $J=$ $8.2,7.8,1.6,2 \mathrm{H}), 7.09$ (dd, $J=8.2,1.1,2 \mathrm{H}), 6.95$ (br.t, $J=8.2,2 \mathrm{H}), 3.33$ $(\mathrm{t}, J=7.4,4 \mathrm{H}), 3.09(\mathrm{t}, J=7.4,4 \mathrm{H}), 2.19$ (quin, $J=7.4,4 \mathrm{H}$ ). HRMS (ESI) calcd for $\mathrm{C}_{28} \mathrm{H}_{25} \mathrm{~N}_{2} \mathrm{O}_{2}\left([\mathrm{M}+\mathrm{H}]^{+}\right): m / z$ 421.1916. Found: $m / z$ 421.1899.

Platinum Complex (13a). A mixture of the ligand (126 mg, $0.3 \mathrm{mmol})$ and potassium tetrachloroplatinate $(124 \mathrm{mg}, 0.3 \mathrm{mmol})$ in acetic acid $(30 \mathrm{~mL})$ was heated under reflux for $14 \mathrm{~h}$. Water $(30 \mathrm{~mL})$ was added, and the solid product was filtered off, washed with water, and dried to give 13a as a yellow solid. Yield $160 \mathrm{mg}(87 \%) .{ }^{1} \mathrm{H}$ NMR $(400.1 \mathrm{MHz}$, $\left.\mathrm{CDCl}_{3}, \mathrm{Me}_{4} \mathrm{Si}\right) \delta 7.73(\mathrm{~s}, 2 \mathrm{H}), 7.49(\mathrm{dd}, J=8.1,1.4,2 \mathrm{H}), 7.41(\mathrm{dd}, J=$ 8.3, 1.1, 2H), $7.29(\mathrm{~m}, 2 \mathrm{H}), 6.62(\mathrm{~m}, 2 \mathrm{H}), 3.26(\mathrm{t}, J=7.4,4 \mathrm{H}), 2.75(\mathrm{t}, J=$ $7.4,4 \mathrm{H}), 1.82(\mathrm{qu}, J=7.4,4 \mathrm{H})$. HRMS (TOF) calcd for $\mathrm{C}_{28} \mathrm{H}_{23} \mathrm{~N}_{2} \mathrm{O}_{2}{ }^{194} \mathrm{Pt}$ $\left([\mathrm{M}+\mathrm{H}]^{+}\right): m / z 613.1386$. Found: $m / z 613.1395$.

\section{ASSOCIATED CONTENT}

\section{S Supporting Information}

The Supporting Information is available free of charge on the ACS Publications website at DOI: 10.1021/acs.inorgchem.7b03175.

Details of the synthesis of tert-butyl isomers $\mathbf{1 2 b}$ and $\mathbf{1 3 b}$, copies of NMR and MASS spectra, additional details for photophysical and electrochemical characterization, and OLED device fabrication (PDF)

\section{AUTHOR INFORMATION}

\section{Corresponding Authors}

*E-mail: f.m.b.dias@durham.ac.uk.

*E-mail: valery.kozhevnikov@northumbria.ac.uk.

ORCID

Piotr Pander: 0000-0003-4103-4154

Frank W. Lewis: 0000-0003-3176-8162

Fernando B. Dias: 0000-0001-9841-863X

Valery N. Kozhevnikov: 0000-0001-7032-8886

Notes

The authors declare no competing financial interest.

\section{ACKNOWLEDGMENTS}

This work was supported by Northumbria University, EU Horizon 2020 research and innovation program under Marie 
Skłodowska-Curie grant agreement no. 674990 (EXCILIGHT), and EPSRC, EP/L02621X/1, and EP/P004873/1. We thank the EPSRC UK National Mass Spectrometry Facility at Swansea University for recording the high-resolution mass spectra.

\section{REFERENCES}

(1) Li, K.; Ming Tong, G. S.; Wan, Q.; Cheng, G.; Tong, W.-Y.; Ang, W.-H.; Kwong, W.-L.; Che, C.-M. Highly Phosphorescent Platinum(II) Emitters: Photophysics, Materials and Biological Applications. Chem. Sci. 2016, 7, 1653 .

(2) Lin, Y.-Y.; Chan, S.-C.; Chan, M. C. W.; Hou, Y.-J.; Zhu, N.; Che, C.-M.; Liu, Y.; Wang, Y. Structural, Photophysical, and Electrophosphorescent Properties of Platinum(II) Complexes Supported by Tetradentate N2O2 Chelates. Chem. - Eur. J. 2003, 9, 1263.

(3) Geissman, T. A.; Schlatter, M. J.; Webb, I. D.; Roberts, J. D. The synthesis of Some Intermediates for Use in the Preparation of Analogs of Salicylaldehyde Ethylenediimine Cobalt ("Salcomine"). J. Org. Chem. 1946, 11, 741 .

(4) (a) Pabst, G. R.; Sauer, J. A New and Simple 'LEGO' System for the Synthesis of 2,6-Oligopyridines. Tetrahedron Lett. 1998, 39, 6687. (b) Pfuller, O. C.; Sauer, J. The New and Simple 'LEGO' System for the Synthesis of Thienyl Substituted 2,6-Oligopyridines. Tetrahedron Lett. 1998, 39, 8821. (c) Kozhevnikov, V. N.; Kozhevnikov, D. N.; Nikitina, T. V.; Rusinov, V. L.; Chupakhin, O. N.; Zabel, M.; Konig, B. A Versatile Strategy for the Synthesis of Functionalized 2,2 '-bi- and 2,2': 6 ',2 '-Terpyridines via their 1,2,4-Triazine Analogues. J. Org. Chem. 2003, 68, 2882. (d) Prokhorov, A. M.; Kozhevnikov, V. N.; Kopchuk, D. S.; Bernard, H.; Le Bris, N.; Tripier, R.; Handel, H.; Koenig, B.; Kozhevnikov, D. N. 1,2,4-Triazine Method of Bipyridine Ligand Synthesis for the Preparation of New Luminescent Eu(III) Complexes. Tetrahedron 2011, 67, 597. (e) Branowska, D.; Wysocki, W.; Olender, E.; Lawecka, J.; Chaciak, B.; Ledwon, P.; Lapkowski, M.; Karczmarzyk, Z. Synthesis, Photophysics and Electrochemical Properties of 1,1'-(2,2'Bithiophene-5, $5^{\prime}$-diyl)bis(cycloalkeno[c]pyridine) as a Result of the Diels-Alder Reaction of 3-(2-Thienyl)-1,2,4-triazine. New J. Chem. 2015, 39, 9672. (f) Branowska, D. A Facile Route to Symmetrical and Unsymmetrical Cycloalkeno[c] fused 2,2'-Bipyridine Ligands via Inverse Electron Demand Diels-Alder Reaction of 5,5'-bi-1,2,4Triazines. Synthesis 2003, 2003, 2096.

(5) (a) Kozhevnikov, D. N.; Kozhevnikov, V. N.; Ustinova, M. M.; Santoro, A.; Bruce, D. W.; Koenig, B.; Czerwieniec, R.; Fischer, T.; Zabel, M.; Yersin, H. Synthesis of Cyclometallated Platinum Complexes with Substituted Thienylpyridines and Detailed Characterization of Their Luminescence Properties. Inorg. Chem. 2009, 48, 4179. (b) Kozhevnikov, V. N.; Donnio, B.; Bruce, D. W. Phosphorescent, Terdentate, Liquid-Crystalline Complexes of Platinum(II): StimulusDependent Emission. Angew. Chem., Int. Ed. 2008, 47, 6286. (c) Santoro, A.; Whitwood, A. C.; Williams, J. A. G.; Kozhevnikov, V. N.; Bruce, D. W. Synthesis, Mesomorphism, and Luminescent Properties of Calamitic 2-Phenylpyridines and Their Complexes with Platinum(II). Chem. Mater. 2009, 21, 3871.

(6) Olszewska, T.; Gajewska, E. P.; Milewska, M.J. Alternative Method for the Synthesis of Imidazo[5,1-f] $[1,2,4] \operatorname{triazin}-4(3 \mathrm{H})$-one - a Substrate for the Preparation of Phosphodiesterase (5) inhibitors. Tetrahedron 2013, 69, 474.

(7) Neunhoeffer, H.; Hennig, H.; Frühauf, H.-W.; Mutterer, M. Zur Synthese von 1, 2, 4-Triazinen. Tetrahedron Lett. 1969, 10, 3147.

(8) (a) Mojzych, M.; Karczmarzyk, Z.; Wysocki, W.; Ceruso, M.; Supuran, C. T.; Kryštof, V.; Urbańczyk-Lipkowska, Z.; Kalicki, P. New Approaches to the Synthesis of Sildenafil Analogues and their Enzyme Inhibitory Activity. Bioorg. Med. Chem. 2015, 23, 1421-1429. (b) Alphonse, F.-A.; Suzenet, F.; Keromnes, A.; Lebret, B.; Guillaumet, G. Copper(I)-Promoted Palladium-Catalyzed CrossCoupling of Unsaturated Tri-n-butylstannane with Heteroaromatic Thioether. Org. Lett. 2003, 5, 803.

(9) (a) Krass, D. K.; Chen, T.-K.; Paudler, W. W. 1,2,4-Triazines X: Dimerizations of 1,2,4-Triazines. J. Heterocycl. Chem. 1973, 10, 343. (b) Krass, D. K.; Paudler, W. W. 1,2,4-Triazines. XII. Syntheses of
5-Carboxarnido-1,2,4-triazines via an Addition-Oxidation Reaction. J. Heterocycl. Chem. 1974, 11, 43.

(10) Branowska, D. A Direct Route to 6,6'-Disubstituted-2,2'Bipyridines by Double Diels-Alder/retro Diels-Alder Reaction of 5,5'bi-1,2,4-Triazines. Molecules 2005, 10, 274.

(11) (a) Data, P.; Pander, P.; Lapkowski, M.; Swist, A.; Soloducho, J.; Reghu, R. R.; Grazulevicius, J. V. Unusual Properties of Electropolymerized 2,7-and 3,6-Carbazole Derivatives. Electrochim. Acta 2014, 128, 430. (b) Cardona, C. M.; Li, W.; Kaifer, A. E.; Stockdale, D.; Bazan, G. C. Electrochemical Considerations for Determining Absolute Frontier Orbital Energy Levels of Conjugated Polymers for Solar Cell Applications. Adv. Mater. 2011, 23, 2367. (c) Bredas, J.-L. Mind the Gap! Mater. Horiz. 2014, 1, 17.

(12) Stephens, P. J.; Devlin, F. J.; Chabalowski, C. F.; Frisch, M. J. Ab Initio Calculation of Vibrational Absorption and Circular Dichroism Spectra Using Density Functional Force Fields. J. Phys. Chem. 1994, 98, 11623.

(13) Neese, F., The ORCA Program System. 2012, 2, 73.10.1002/ wcms.81.

(14) (a) Fonseca Guerra, C.; Snijders, J. G.; te Velde, G.; Baerends, E. J. Towards an Order-N DFT Method. Theor. Chem. Acc. 1998, 99, 391. (b) van Gisbergen, S. J. A.; Snijders, J. G.; Baerends, E. J. Implementation of Time-Dependent Density Functional Response Equations. Comput. Phys. Commun. 1999, 118, 119. (c) ADF2009.01, SCM. https://www.scm.com/.

(15) Wang, F.; Ziegler, T. A Simplified Relativistic Time-Dependent Density-Functional Theory Formalism for the Calculations of Excitation Energies Including Spin-Orbit Coupling Effect. J. Chem. Phys. 2005, 123, 154102 .

(16) (a) Lenthe, E. V.; Baerends, E. J.; Snijders, J. G. Relativistic Regular Two-Component Hamiltonians. J. Chem. Phys. 1993, 99, 4597. (b) van Lenthe, E.; Baerends, E. J.; Snijders, J. G. Relativistic Total Energy Using Regular Approximations. J. Chem. Phys. 1994, 101, 9783.

(17) (a) Graves, D.; Jankus, V.; Dias, F. B.; Monkman, A. Photophysical Investigation of the Thermally Activated Delayed Emission from Films of m-MTDATA: PBD Exciplex. Adv. Funct. Mater. 2014, 24, 2343. (b) Jankus, V.; Chiang, C.-J.; Dias, F.; Monkman, A. P. Deep Blue Exciplex Organic Light-Emitting Diodes with Enhanced Efficiency; P-type or E-type Triplet Conversion to Singlet Excitons? Adv. Mater. 2013, 25, 1455. (c) Aydemir, M.; Jankus, V.; Dias, F. B.; Monkman, A. The Key Role of Geminate Electron-Hole Pair Recombination in the Delayed Fluorescence in Rhodamine 6G and ATTO-532. Phys. Chem. Chem. Phys. 2014, 16, 21543.

(18) (a) Kozhevnikov, V. N.; Zheng, Y.; Clough, M.; Al-Attar, H. A.; Griffiths, G. C.; Abdullah, K.; Raisys, S.; Jankus, V.; Bryce, M. R.; Monkman, A. P. Cyclometalated Ir(III) Complexes for High-Efficiency Solution-Processable Blue PhOLEDs. Chem. Mater. 2013, 25, 2352. (b) Benjamin, H.; Zheng, Y.; Batsanov, A. S.; Fox, M. A.; Al-Attar, H. A.; Monkman, A. P.; Bryce, M. R. Sulfonyl-Substituted Heteroleptic Cyclometalated Iridium(III) Complexes as Blue Emitters for SolutionProcessable Phosphorescent Organic Light-Emitting Diodes. Inorg. Chem. 2016, 55, 8612.

(19) Jou, J.-H.; Hsieh, C.-Y.; Chen, P.-W.; Kumar, S.; Hong, J. H. Candlelight Style Organic Light-Emitting Diode: a Plausibly HumanFriendly Safe Night Light. J. Photonics Energy 2014, 4, 043598.

(20) Jou, J.-H.; Su, Y.-T.; Liu, S.-H.; He, Z.-K.; Sahoo, S.; Yu, H.-H.; Chen, S.-Z.; Wang, C.-W.; Lee, J.-R. Wet-process Feasible Candlelight OLED. J. Mater. Chem. C 2016, 4, 6070.

(21) In response to a reviewer's comments on the unusually high EQE and CE values based on an estimation from the PLQY, the measurements have been repeated and were found to show reproducible values. The detailed mechanism and reasons for these may require further study. 